\title{
Editorial
}

\section{Making sense of the duality of social cohesion}

http://dx.doi.org/10.17159/2413-3108/2016/v0n55a763

This edition of South African Crime Quarterly is a special edition dedicated to investigating the role of social cohesion in understanding and addressing the problem of violence in South Africa.

Social cohesion is a broad concept, but can be summarised briefly as referring to the factors that 'hold a society together'. ${ }^{1}$ The term has been utilised to denote a broad array of social characteristics that are seen to contribute to connectedness and solidarity at local and national levels. These include common values and identity, feelings of belonging, citizen participation in common organisations, and community cooperation and interaction. It extends further to encompass those things that are necessary for sustaining (holding together) a democratic nation-state, such as political legitimacy and democratic participation. By implication, a society lacking cohesion would be one that displayed social disorder and conflict, disparate moral values, extreme social inequality, low levels of social interaction between and within communities, and low levels of place attachment - characteristics that are familiar to South Africa. ${ }^{2}$ Collective efficacy, a more recent development of the concept of social cohesion, refers to how social cohesion can prevent violence when it is translated into collective action for the 'common good' at neighbourhood level. ${ }^{3}$

While a lack of social cohesion is theorised to result in a state of disorder or conflict, low levels of social cohesion are also seen to undermine the effectiveness of crime prevention initiatives at local level. International studies have found that communities with the highest crime and violence rates are often those who are unable or reluctant to organise collaboratively as a result of lack of trust. But is this the case in South Africa?

This edition of the SACQ seeks to critically interrogate the concept of social cohesion and its meaning in South Africa. Thus far, the leading policy and academic work on social cohesion and collective efficacy has taken place in countries in the global North and has been oriented to address the problems of division in these contexts. In South Africa, we face a different set of challenges in a country defined by its heterogeneity and inequality. One of our primary challenges is to determine how to constitute a new democratic nation-state, based on relationships of solidarity and connection between citizens, after the many decades of conflict and division that tore apart our social fabric and while inequality remains a stubborn feature of our landscape.

While the term 'social cohesion' has been incorporated into government discourse over the past decade, and efforts have been made to indigenise the concept by incorporating local concepts such as ubuntu into our notion of social cohesion, there has been very little empirical investigation into the lived meaning and conditions of social cohesion in the South African context, or analysis of how bonds between citizens may help to prevent or indeed increase violence. The articles in this edition attempt to address some of these empirical and conceptual gaps and go some way towards revealing the duality of social cohesion that can either work towards or against peace.

Three of the articles in this edition feature research findings from studies in the Western Cape, which is apt given the high levels of heterogeneity and violence in the province.

Don Pinnock takes us back to District Six to grapple with the consequences of razing that multi-racial, multicultural community and the legacy of social dislocation this act of violent destruction left. He explores the 
tangible and immaterial factors that constituted the social cohesion of District Six and paints a picture of a heterogeneous community that, despite poverty and even violence, cohered in the face of state legislated racial segregation. It is this sense of connection that former residents still yearn for and its loss that informs the marginalisation and alienation of the descendants of those who lived there.

Vanessa Barolsky's article, based on an ethnographic study in Khayelitsha, critically interrogates the meaning of international conceptions of social cohesion and their relevance to the South African context. She shows that this large urban township is characterised by high levels of informal social organisation and interaction and a deeply engrained ethic of care implicitly based on the South African ethos of ubuntu. People do intervene on each other's behalf as a part of daily life. Yet these same close ties can sanction and enable violence as citizens cohere to violently respond to individuals identified as 'other': 'criminals' or foreign nationals. Here, as in several other communities, taxi associations play a key role in the violent regulation of social relations, particularly the control of youth gang violence in a context where citizens have an ambiguous relation to the law and formal state regulation. It is in this complex and contested context that the Violence Prevention through Urban Upgrading (VPUU) project has sought to intervene by creating a model for preventing violence. The VPUU is an internationally funded and conceptualised violence prevention intervention that posits a positive change in social relations based on urban upgrading and a vision of an ordered city and classic Western entrepreneur. Barolsky shows that the value-laden project faces considerable difficulty in implementing its vision in the informal environment of Khayelitsha, and may have undermined social cohesion as a result.

Laurence Piper and Joanna Wheeler investigate the complex contemporary conditions of social cohesion in the Western Cape informal settlement Imizamo Yethu. They show how this community is characterised by a gradual unravelling of the cohesion that tenuously existed under the leadership of the South African National Civic Organisation (SANCO) for a few years after 1994. However, they argue that while violence is a constant presence in social life, it is, perhaps surprisingly, not used by political leaders to retain control - contrary to international literature that hypothesises that weak rule is associated with violent contests over political power. Instead, in Imizamo Yethu, violence is used to underpin other forms of coercive power, such as that exercised by taxi associations. As local rule has weakened, these types of violence have increased in the absence of effective civic regulation. In this context, like in Khayelitsha, violence becomes a means of policing certain types of parochial cohesion and morality, for example through a recent violent mobilisation against drug gangs, which led to the killing of two gang leaders whose violence had deeply disturbed community peace.

Moving away from the Western Cape, Malose Langa and his colleagues analyse the impact of the Community Work Programme (CWP) on social cohesion and violence. They consider local initiatives that have sought to address violence through diverse projects that range from clearing grass in crime 'hotspots' to providing recreational activities for young men, integrating ex-offenders, assisting in the implementation of the Domestic Violence Act, and creating campaigns against gang violence. The research on which this article is based found that the CWP appears to have a positive effect on social cohesion in many of the areas where it is implemented. It does so by creating networks between citizens that help them to mobilise human and social capital to address social problems (collective efficacy at work). Yet the CWP is also shown to be vulnerable to political contestation and gatekeeping, particularly in relation to controlling access to the employment opportunities it provides. In such instances social cohesion is undermined and divisions exacerbated.

In their article Ben Roberts and Steven Gordon examine the potentially corrosive effects of fear of crime on the social fabric through an analysis of national level survey data from the South African Social Attitudes Survey (SASAS). The article investigates two competing models that hypothesise the impact of fear of crime on the social fabric. One holds that escalating fear of crime can inhibit social interaction and lead to social withdrawal. This weakens the ability of local communities to collectively address problems, undermining both collective efficacy and social cohesion. The other model posits that fear of crime may enhance community solidarity by motivating residents to come together and respond collectively to the problem of crime. The findings suggest 
that fear of crime has only a marginal negative impact on social trust in South Africa, which may indicate that South Africans are resilient to fear of crime, but could also reflect that social trust in the country is already low. The authors show that fear of crime has a more robust link to dissatisfaction with what Roberts and Gordon call 'civic cohesion', which relates to issues of political legitimacy and democratic participation rather than to social cohesion more broadly. In other words, fear of crime fuels a lack of faith in the government, particularly in the police, rather than undermining social cohesion.

Anine Kriegler and Mark Shaw investigate the relationship between social cohesion, fear of crime and reported victimisation through a survey of 400 households in Cosmo City, a new mixed-use settlement north-west of Johannesburg, explicitly designed for social inclusion and cohesion. They find that the settlement is indeed characterised by high levels of social cohesion if evaluated in terms of local place attachment, with a significant proportion of residents expressing attachment to the neighbourhood in which they live within Cosmo City. The results demonstrate complex linkages between incidence of crime, fear of crime and social cohesion. In general residents expressed lower levels of fear of crime than citizens canvassed in the country's National Victimisation Survey. On the other hand, residents reported a statistically improbably high experience of crime, including violent crime. They conclude that social cohesion between neighbours may lead to a heightened perception of risk through 'talk about crime', but at the same time, cohesion between neighbours may mitigate the impact of this perception of risk, reducing levels of fear of crime.

What emerges from these articles is a complex picture that does not simplistically support a hypothesis that high levels of social cohesion reduce violence. In the wake of the entrenched fracturing of social cohesion by apartheid, communities across South Africa still cohere in multifaceted and paradoxical ways that seem to frequently (and unsurprisingly) support, rather than resist, violence. In these contexts, violence may become an organising principle of localised and defensive forms of social cohesion, disputing the relation between social cohesion and order articulated in international literature. Here the research indicates that violent forms of cohesion are utilised by citizens to manage a deeply contested political and social environment.

\section{Vanessa Barolsky \\ (Guest editor)}

\section{Notes}

1 Republic of South Africa, The Presidency, Social cohesion \& social justice in South Africa, Pretoria: Policy Co-ordination, Advisory Services, 2004, iv.

2 Ray Forrest and Ade Kearns, Social cohesion, social capital and the neighbourhood, Urban Studies, 38:12, $2001,2125-2143$.

3 RJ Sampson, SW Raudenbush and F Earls, Neighborhoods and violent crime: a multilevel study of collective efficacy, Science, 277, 1997, 918-924.

\section{Policy on the use of racial classifications in articles published in South African Crime Quarterly}

Racial classifications have continued to be widely used in South Africa post-apartheid. Justifications for the use of racial descriptors usually relate to the need to ensure and monitor societal transformation. However, in the research and policy community racial descriptors are often used because they are believed to enable readers and peers to understand the phenomenon they are considering. We seem unable to make sense of our society, and discussions about our society, without reference to race.

South African Crime Quarterly (SACQ) seeks to challenge the use of race to make meaning, because this reinforces a racialised understanding of our society. We also seek to resist the lazy use of racial categories and descriptors that lock us into categories of identity that we have rejected and yet continue to use without critical engagement post-apartheid. Through adopting this policy SACQ seeks to signal its commitment to challenging the racialisation of our society, and racism in all its forms.

We are aware that in some instances using racial categories is necessary, appropriate and relevant; for example, in an article that assesses and addresses racial transformation policies, such as affirmative action. In this case, the subject of the article is directly related to race. However, when race or racial inequality or injustice is not the subject of the article, $S A C Q$ will not allow the use of racial categories. We are aware that some readers might find this confusing at first and may request information about the race of research subjects or participants. However, we deliberately seek to foster such a response in order to disrupt racialised thinking and meaning-making. 